\title{
КОМБИНИРАНА ФОТОТЕРАПИЯ ПРИ ХРОНИЧНИ ТЕМПОРОМАНДИБУЛАРНИ ДИСФУНКЦИИ
}

\author{
Савина Ненчева-Свещарова ${ }^{1}$, Васил Свещаров $^{2}$, Цветан Тончев ${ }^{3}$

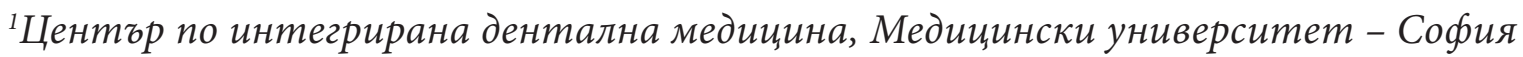 \\ ${ }^{2}$ Катедра „Орална и тицево-челюстна хирургия“, Медицински университет - София \\ ${ }^{3}$ Катедра „Орална и лицево-челюстна хирургия и специална образна диагностика“, \\ Медицински университет - Варна

\section{COMBINED PHOTOTHERAPY IN CHRONIC TEMPOROMANDIBULAR DISORDERS} \\ Savina Nencheva-Svechtarova ${ }^{1}$, Vassil Svechtarov ${ }^{2}$, Tsvetan Tonchev ${ }^{3}$ \\ ${ }^{1}$ Center for Integrated Dental Medicine, Medical University - Sofia \\ ${ }^{2}$ Department of Oral and Maxillofacial Surgery, Medical University - Sofia \\ ${ }^{3}$ Department of Oral and Maxillofacial Surgery and Special Imaging Diagnostics, \\ Medical University of Varna
}

\begin{abstract}
PE3ЮME
Целта на това изследване е да провери клиничната ебективност на комбинираната лазерна (галиево-алуминиево-арсениден лазер, GaAlAs; 785nm) със суперлуминисиентно диодна (SLD; 633 nm) бототерапия (MedX 1100 устройство) при течение на пациенти с темпоромандибуларни дисбункиии и миобасциална болкова симптоматика. Резултатите om t-test $u$ Wilcoхо тест показват статистически значима редукиия на болката ( $><0: 05)$ главно за темпоромандибуларната става и за масетерните мускули. Статистически значим резултат се отчита и при преодоляването на артроu миогенните контрактури. В заключение, комбинираната фототерапия $c$ описаните технически параметри и методика е ефективна при симптоматичното течение на болково свързаните темпоромандибуларни дисбункции.
\end{abstract}

Ключови думи: галиево-алуминиевоарсениден лазер, суперлуминисиентни диоди, темпоромандибуларни дисбункции

\begin{abstract}
The objective of this study was to test the clinical effectiveness of the gallium-aluminum-arsenide laser (GaAlAs; 785nm) and superluminiscent diods (SLD; $633 \mathrm{~nm}$ ) combined phototherapy (MedX 1100 device) for the treatment of patients with temporomandibular disorders and myofascial pain symptoms. The results demonstrated a positive effect in the pain relief. A significant reduction $(p<0: 05)$ in the pain level was observed mainly for the temporomandibular joints and for the masseter muscles using paired samples t-test and Wilcoxon signed rank test. Statistically significant results were also registered in overcoming the arthro and myogenic contractures. In conclusion, combined quantum phototherapy carried out described technical parameters and methodology is an effective symptomatic treatment for pain - related temporomandibular disorders.
\end{abstract}

Keywords: gallium-aluminum-arsenide laser GaAlAs, $S L D$, temporomandibular disorders 


\section{ВЪВЕДЕНИЕ}

Темпоромандибуларни дисфункции (ТМД) е събирателен термин, който обхваща всички мускулно-скелетни патологични състояния, свързани с темпоромандибуларната става и свързаните с нея органи и структури. Те се характеризират със специфична болкова симптоматика и ставно-мускулни дисфункции, като засягат до 12\% от популациите на развитите държави $(15,16)$. Диагностиката на тези патологични състояния винаги е била обект на множество дискусии, но през 2014 година след реализирането на мащабните Validation Project и ТMJ Impact Project на National Institute for Dental and Craniofacial Research (NIDCR) и International Association for Dental Research (IADR) бе въведена нова таксономия на базата на дефинициите на American Academy of Orofacial Pain (AАOP), диагностични критерии и методика, предназначена за клинична и изследователска дейност (DC/TMD, DIagnostic Criteria for Temporomandibular Disorders) $(15,17)$. В тях се включват важни допълнения към RDC/TMD, изключват се някои диагнози и се модифицират други. Методиката DC/TMD е синхронизирана с нозологичните единици от Десета ревизия на Международната класификация на болестите, а описаните в нея критерии по Axis I имат чувствителност $\geq 0.86$, специфичност $\geq 0.98$, като междуизследователската надеждност на методиката е отлична (kappa $\geq 0.85)(17)$. Хронифициране на темпоромандибуларните дисфункции се наблюдава при 5-15\% от всички симптоматични пациенти и за такива се считат тези, при които болковата симптоматика е персистираща или ремитираща за период най-малко от шест месеца с обективно палпируеми тригерни точки (2). Пациентите с пролонгирана болкова симптоматика по правило трудно се повлияват от повечето познати методи за лечение и представляват особен диагностичен и терапевтичен проблем за клиницистите.

За терапевтични цели могат да бъдат използвани разнообразни светлинни източници като лазери, суперлуминисцентни диоди (SLD) или светлинно емитиращи диоди (LED). Отделената от тях енергия осигурява временно повишение на микроциркулацията, временно облекчение на болката в малките мускули и стави при артропатии, релаксация на мускулатурата и облекчаване на мускулните спазми $(1,4,8,14,19)$. Най-често се използва инфрачервеният галиево-алуминиево-арсениден лазер, опериращ в диапазона 780$870 \mathrm{~nm}$. Brosseau et al (5) анализират литературата относно приложението на нискоинтензитет- ната лазерна терапия при артрити и обобщават, че тя води до краткотрайно облекчение на болката и сутрешната скованост при ревматоиден артрит, докато за остеоартритите има противоречащи и недостатъчни данни. Относно миофасциалните болки Laakso et al (10) подкрепят положителния лечебен ефект от лазерна терапия с 670 $\mathrm{nm}, 10 \mathrm{~mW}$ и при $820 \mathrm{~nm}, 25 \mathrm{~mW}$, като отчитат, че при $820 \mathrm{~nm}$ ефектът от лечението е по-голям. Simonovic et al (18) изследват 243 пациенти с доказани пускови точки и установяват, че болката намалява с повече от 70\% при третиране с $820 \mathrm{~nm}$. Много от клиницистите работят с широк диапазон на технически параметри и резултатите им са твърде разнородни. Fikachkova et al $(11,12)$ третират 61 пациенти с темпоромандибуларни артралгии и миофасциални болки с дози от $10 \mathrm{~J} / \mathrm{cm}^{2}$ и $15 \mathrm{~J} / \mathrm{cm}^{2}$ c GaAlAs лазер с мощност $400 \mathrm{~mW}$, дължина на вълната $830 \mathrm{~nm}, 10$ лечебни процедури и съобщават за положителен болково редуциращ ефект, особено при хроничните случаи. Относно дозировката общоприет е принципът, че колкото по-хроничен е един проблем, толкова повече енергия се изисква за постигането на терапевтичен ефект. Carrasco et al $(6,7)$ прилагат GaAlAs лазер при пациенти с миофасциална симптоматика и наблюдават значително намаляване на болката. Baxter et al (3) предлагат енергийна плътност от 8 до $12 \mathrm{~J} / \mathrm{cm}^{2}$ за темпоромандибуларната става. Начинът на приложение е също толкова важен, колкото и дозата - най-ефективният метод е посредством прилагане на умерен натиск върху засегнатия орган. Каменова (1) установява, че най-добри резултати при лечението на ТМД се получават при комбинираните методи на лазерна терапия и особено при биосинергичния феномен и комплексна терапевтична програма. Maia et al (13) извършват систематичен анализ на четиринадесет статии за употребата на нискоинтензитетните лазери при лечение на ТМД, в тринадесет от които се отчита редукция на болката. Според метаанализ на Chang et al (9) аналгетичният ефект постигнат с лазер с дължина на вълната от 830 и $780 \mathrm{~nm}$ е умерен до силен.

\section{ЦЕЛ}

Целта на това изследване е да се извърши клинико-статистически анализ на редукцията на интензитета на болката и преодоляването на артро- и миогенните контрактури при комбинирано лечение на хроничните темпоромандибуларни дисфункции с галиево-алуминиево-арсениден лазер $(785 \mathrm{~nm})$ и суперлуминисцентнодиодна червена светлина $(633 \mathrm{~nm})$ чрез устройството 
MedX 1100 Phototherapy device. Изследването се отнася за 12-те най-чести, болково свързани темпоромандибуларни дисфункции, които са обект на методиката DC/TMD.

\section{МАТЕРИАЛ И МЕТОДИ}

Това проучване включва 62 пациенти - 7 мъже $(11,29 \%)$ и 55 жени (88,70\%), на възраст от 21 до 74 години (средно - 42,77; SD - 13,94) с клинични симптоми на хронични ставни и/или миофасциални болки с различна етиология. Дванадесетте често срещани дисфункции, които се констатират в изследваната група, включват артралгия, миалгия, миофасциална болка, локална миалгия, миофасциална болка с отразена такава, четири вида дискови дислокации, дегенеративни ставни заболявания, сублуксация и главоболие, свързано с ТМС. наличието на ерозии, остеофити, субхондрална склероза или субхондрални кисти, като в отделни случаи са прилагани компютърна томография и/или и магнитен резонанс. При определяне на необходимите образно-диагностични изображения се спазва принципът ALARA (as low as reasonably achievable) (2). Наличието на системни артропатии като ревматоиден артрит се приемат за достоверни след удовлетворяването на диагностичните критерии и представянето на официална документация, доказваща заболяването.

За целите на настоящото изследване се използва комбинирано лазерно устройство, снабдено със суперлуминисцентни диоди. Бяха приложени trigger point ориентирани лазерни апликации чрез MedX 1100 конзола с три GaAlAs лазерни диода, $785 \mathrm{~nm}, 3 \times 33 \mathrm{~mW}, 100 \mathrm{~s}, 8 \mathrm{~J} / \mathrm{cm}^{2}$ за участък и SLD с червена светлина $(633 \mathrm{~nm}, 200 \mathrm{~mW}$, $\left.300 \mathrm{~s}, 8 \mathrm{~J} / \mathrm{cm}^{2}\right)$. SLD устройството плътно приляга

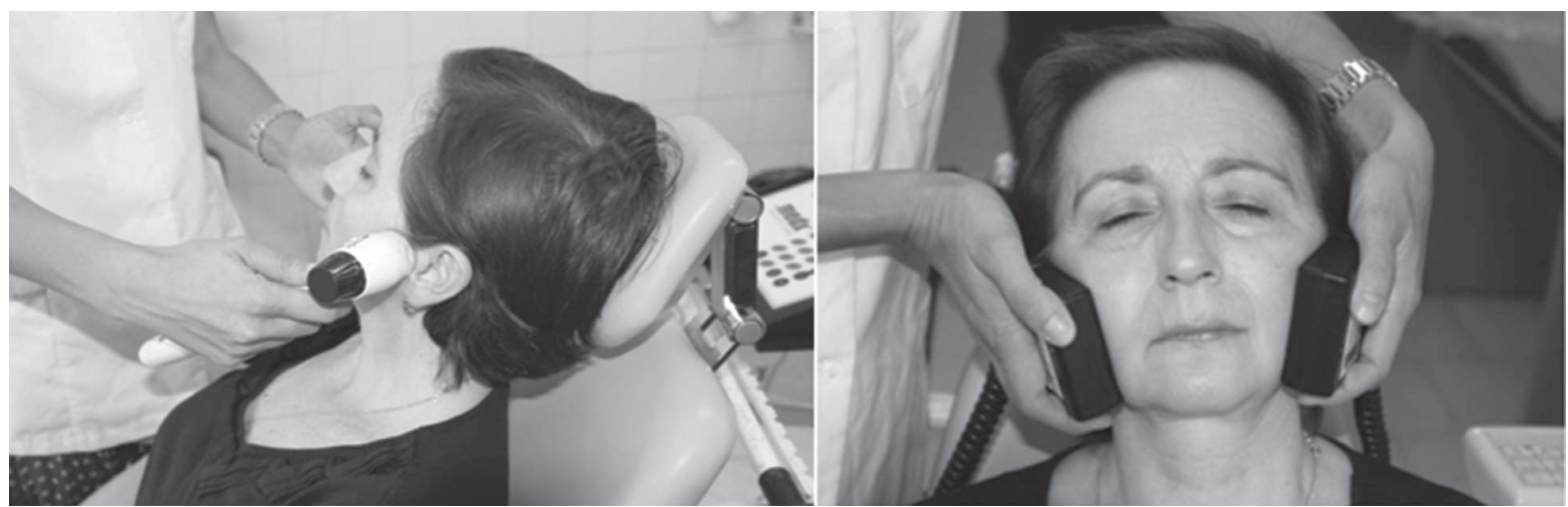

Фиг. 1а,б. Лазерна апликация в областта на темпоромандибуларната става (а) и SLD в областта на масетерните мускули двустранно (б)

Диагностиката се извършва посредством диагностичните критерии и методологичния инструментариум на DC/TMD. Артралгията се доказва чрез палпация на латералния полюс на ставата и преаурикуларната зона до потвърждение на позната болка (familiar pain) и по време на функция; миогенните тригерни точки чрез плоска и обемна палпация на дъвкателните и цервикалните мускули. Данните за локализацията, интензитета на болката, лазерните апликации и дозите се нанасят в индивидуална болкова карта. Интензитетът на болката се отчита по 10-степенна визуална аналогова скала (VAS). Дегенеративно костно-ставните заболявания - остеоартрит и остеоартроза - се потвърждават при наличие на хипомобилност на кондила, мандибуларни девиации и специфични аускултационни шумови находки на ставите във функция и при палпация; рентгенологично - чрез панорамни рентгенографии и ставни центражи за към плоските повърхностно разположени мускули - темпоралния, масетера и трапециуса. В настоящото изследване е прилагана точкова и сканираща техника на апликация в локусите на палпаторно диагностицираните пускови точки. Накрайникът се придържа под прав ъгъл, в плътен контакт и умерен натиск с третираната повърхност. Болковият интензитет и неасистираното интеринцизално отстояние са изследвани преди и след извършването на шест процедури (3 процедури седмично) на комбинирана фототерапия.

За статистически анализ на данните са използвани Student's t-test за сдвоени извадки и кореспондиращият непараметричен Wilcoxon test. Обработката на данните е чрез статистическия софтуер STATISTICA. При t-тестовете са използвани стойностите на интензитета на болката преди и след терапия за всеки отделен пациент. 


\section{РЕЗУЛТАТИ И ОБСЪЖДАНЕ}

Честотата на провеждане на процедурите е 3 пъти седмично за 2 до 3 седмици до постигане на резултат - редуциране или елиминиране на болковата симптоматика, преодоляване на контрактурата и дисфункцията. Средният брой на процедурите за цялата изследвана група е 6,59 (min6, max-16). При 50 (80,64\%) от пациентите ефективна фототерапия се реализира в 6 сесии, а при 12 (19,35\%) - за по-продължителен период. Дозирането при хрониците стартира с по-ниски дози - по $8 \mathrm{~J} / \mathrm{cm}^{2}$ за всяка от доказаните тригерни точки на ставите и/или мускулите, а при неудовлетворителен лечебен ефект тя се увеличава и прилага за по-продължителен период. Така средната обща доза за пациент в изследваната група е $33,51 \mathrm{~J}$, средната аплицирана лазерна доза е 21,06 $\mathrm{J}$, а средната SLD доза е $12,25 \mathrm{~J}$. е ефективна като симптоматична болково редуцираща монотерапия при $96,77 \%$ от пациентите, като следва да се има предвид, че етиологичните фактори и разпределението на случаите по диагностични подгрупи е твърде разнородно, т.е. тя покрива широк спектьр от патологични болково свързани състояния. От цялата изследвана група само при двама пациенти не се постигна терапевтичен ефект. Първият случай е на 44-годишна жена с манифестна хабитуална двустранна луксация, деформация (flattening) във формата на кондилите, предни дискови дислокации без редукция с ограничено отваряне (33 мм - артрогенен тип контрактура), миофасциална палпаторна болкова симптоматика в темпоралния, инсерциите на медиалния птеригоиден и на масетерния мускул едностранно, с дълбока отразена болка към фаринкса и моларната област на до-

Табл. 1. Student's t-test, Wilxocon test и процент на редукцията на болковия интензитет по органи преди и след фототерапията

\begin{tabular}{|l|c|c|c|c|c|c|c|}
\hline Орган & $\begin{array}{c}\text { Болка } \\
\text { (VAS) }\end{array}$ & SD & N & t & p & $\begin{array}{c}\text { Wilxocon } \\
\text { test }\end{array}$ & $\begin{array}{c}\text { Редукция } \\
\text { на болката }\end{array}$ \\
\hline ТМС едностранно преди лечението & 6,131 & 1,7 & & & & & \\
\hline ТМС едностранно след лечението & 1,052 & 1,0 & 38 & 19,16 & 0,000001 & reject H0 & $82,84 \%$ \\
\hline ТМС двустранно преди лечението & 6,476 & 1,6 & & & & & \\
\hline ТМС двустранно след лечението & 1,142 & 1,2 & 21 & 13,80 & 0,000001 & reject H0 & $82,36 \%$ \\
\hline Тетроralis едностранно преди лечението & 6,2 & 1,3 & & & & & \\
\hline Tетроralis едностранно след лечението & 2,2 & 2,7 & 5 & 3,81 & 0,018878 & reject H0 & $64,51 \%$ \\
\hline Мasseter едностранно преди лечението & 5,346 & 1,4 & & & & & \\
\hline Маsseter едностранно след лечението & 0,423 & 0,8 & 26 & 15,9 & 0,000001 & reject H0 & $92,08 \%$ \\
\hline Мasseter двустранно преди лечението & 5,692 & 1,6 & & & & & \\
\hline Маsseter двустранно след лечението & 0,615 & 1,3 & 13 & 10,43 & 0,000001 & reject H0 & $89,07 \%$ \\
\hline $\begin{array}{l}\text { Sternocleidomastoideus едностранно } \\
\text { преди лечението }\end{array}$ & 5,555 & 1,5 & & & & & \\
\hline $\begin{array}{l}\text { Sternocleidomastoideus едностранно след } \\
\text { лечението }\end{array}$ & 0,666 & 1,1 & 9 & 9,07 & 0,000017 & reject H0 & $88,01 \%$ \\
\hline
\end{tabular}

Статистически значими резултати за редукция на интензитета на болката (Табл. 1) се констатираха едностранно и двустранно за темпоромандибуларните стави и за масетерите, а едностранно при темпоралния и при стерноклейдомастоидния мускул.

В настоящото изследване установихме, че дози от $10 \mathrm{~J} / \mathrm{cm}^{2}$ за темпоромандибуларната става и $8 \mathrm{~J} / \mathrm{cm}^{2}$ за мускулите са достатъчни за постигане на лечебен ефект. Самостоятелно приложена, комбинираната лазерна с червена фототерапия лната челюст. Вторият случай е на 36-годишен мъж с двустранна сублуксация, пристъпна болезненост (спазми) на латералния птеригоиден мускул едностранно, провокирани от студови и/ или барометрични промени или при палпация на дисталния участък на ипсилатералния максиларен тубер, с отразена болка към максиларния синус и горните молари. Пациентът е многократно обследван ото- и неврологично, като в диференциалнодиагностично отношение е отхвърлена всяка друга патология, различна от темпоро- 
мандибуларната. Тези единични случаи подсказват, че при някои хипермобилни състояния самостоятелно приложената квантова фототерапия не винаги постига желания резултат и тогава следва да се включат медикаментозни, други физиотерапевтични и/или ортопедични средства.

По отношение на другия клинично значим въпрос - за преодоляването на контрактурите - резултатите показват статистически значимо увеличение на интеринцизалното отстояние след приложената терапия (Табл. 2). Подобрението по този показател се отчита при някои от пациентите и след първата процедура. Освен тригерно ориентираните лазерни апликации SLD терапията практически обхваща цялата площ на повърхностните и дълбоките дялове на масетерните мускули и това следва да се отчита при преодоляването на миогенните контрактури. чаите, при които не се наблюдава ефект. Trigger point методът на апликация копира болковата симптоматика в болшинството от случаите след втората или третата процедура, а в някои случаи и след първата. В преобладаващата част от случаите при обща еднократна доза до $30 \mathrm{~J}$ терапевтичният курс рядко надхвърля 6 процедури, т.е. лечебният период варира между 2 и 3 седмици.

\section{ЛИТЕРАТУРА}

1. Каменова Ю. Лазерно асистирано лечение на смущенията на долночелюстните стави. Проблеми на денталната медицина, 2013,39, 51-59

2. American Association of Oral and Maxillofacial Surgeons. Parameters of Care: Clinical Practice Guidelines for Oral and

Табл. 2. Student's t-test - интеринцизално отстояние преди и след фототерапията

\begin{tabular}{|l|c|c|c|c||c|}
\hline Интеринцизално отстояние & Mean & SD & N & T & P \\
\hline Преди фототерапията & 39,629 & 11,7 & & & \\
\hline Сред фототерапията & 43,290 & 6,9 & 62 & $-4,41$ & 0,000042 \\
\hline
\end{tabular}

Настоящото изследване доказва ефективността на комбинираната лазерна със суперлуминисцентнодиодна фототерапия при хроничните темпоромандибуларни дисфункции. В повечето от изследваните органи редукцията на болката е над 80\%, а при масетерите - над 90\%. Сравнена с резултатите на други автори, които представят данни за болковата редукция от монолазерна терапия, базирана на сходни технически параметри (18), комбинираната е по-ефективна. За детайлното изясняване на тези въпроси обаче са необходими допълнителни проучвания, които да са базирани не само върху ефекта при третираните органи, но и да са съотнесени към конкретното темпоромандибуларно заболяване, диагностицирано по общоприета, стандартизирана методика. Това се налага, тъй като клиничните ни наблюдения показват, че резултатите зависят и от конкретната диагноза, и от етиологичните фактори, отговорни за развитието на дисфункцията.

\section{ЗАКЛЮЧЕНИЕ}

Ефективността на симптоматичното лечение с комбинирана лазерна и SLD фототерапия по прилаганата методика е висока - при артралгиите, миофасциалните болки и при преодоляването на миогенните контрактури. Единични са слу-
Maxillofacial Surgery (AAOMS ParCare 2012). Journal of Oral and Maxillofacial Surgery. 2012, 70, 204-232

3. Baxter G, Diamantopoulos C, O'Kane S et al. Therapeutic Lasers Theory and Practice. 1997, Churchill Livingstone, New York, 208-209

4. Bjordal J, Couppe C, Chow R et al. A systematic review of low level laser therapy with location-specific doses for pain from chronic joint disorders. The Australian journal of physiotherapy. 2003, 49,107-116

5. Brosseau L, Welch V, Wells G et al. Low level laser therapy for osteoarthritis and rheumatoid arthritis: a meta-analysis. Journal of Rheumatology. 2000, 27,1961-1969

6. Carrasco T, Gnerisol L, Gnerisol D et al. Evaluation of low intensity laser therapy in myofascial pain syndrome - Cranio, 2009, 27, 243-247.

7. Carrasco T, Mazzetto M, Mazzetto R et al. Low intensity laser therapy in temporomandibular disorder: a phase II double-blind study. Cranio, 2008, 26, 274-81 
8. Cetiner S, Kahraman S, Yucetas S. Evaluation of low-level laser therapy in the treatment of temporomandibular disorders. Photomed Laser Surg. 2006, 24, 637-641

9. Chang $\mathrm{W}$, Lee $\mathrm{C}$, Lin $\mathrm{H}$ et al. A Meta-analysis of Clinical Effects of Low-level Laser Therapy on Temporomandibular Joint Pain. J Phys Ther Sci, 2014, 26, 1297-1300.

10. Laakso EL, Richardson C, Cramond T. Pain scores and side effect in response to low level laser therapy for myofascial trigger points. Laser Ther, 1997, 9, 67-72

11. Fikackova H, Dostalova T, Vosicka R et al. Arthralgia of the temporomandibular joint and low-level laser therapy. Photomedicine and Laser Surgery. 2006, 24, 522-527

12. Fikackova H, Dostalova T, Navratil L et al. Effectiveness of low-level laser therapy in temporomandibular joint disorders: a placebo-controlled study. Photomedicine and Laser Surgery, 2007, 25, 297-303

13. Maia M, Bonjardin L, Quintans S et al. Effect of low-level laser therapy on pain levels in patients with temporomandibular disorders: a systematic review. J Appl Oral Sci, 2012, 20, 594-602

14. Mazzetto M, Carrasco T, Bidinelo E et al. Low intensity laser application in temporomandibular disorders: a phase I double-blind study.Cranio, 2007, 25, 186-192

15. Peck C, Goulet J, Lobezzoo F et al. Expanding the taxonomy of the diagnostic criteria for temporomandibular disorders. Journal of Oral Rehabilitation. 2014, 41, 2-23

16. Scrivani S, Keith D, Kaban L. Temporomandibular Disorders. N Engl J Med, 2008; 359, 2693-2705

17. Schiffman E, Ohrbach R, Truelove E et al. Diagnostic Criteria for Temporomandibular Disorders (DC/ TMD) for Clinical and Research Applications: recommendations of the International RDC/TMD Consortium Network and Orofacial Pain Special Interest Group. J Oral Facial Pain Headache, 2014, 28, 6-27

18. Simonovic Z. LLLT with trigger points technique: a clinical study on 243 patients. Journal of Clinical Laser Medicine and Surgery, 1996,14, 163-167
19. Venancio R, Camparis CM, Lizarelli R. Low intensity laser therapy in the treatment of temporomandibular disorders: a doubleblind study.J Oral Rehabil, 2005, 32, 800-807 